DOI 10.26726/2305-4484-2017-3-36-43

УДК 338.48

ФЁДОРОВА МАРИНА ЮРЬЕВНА

аспирант ФБГБУН «Института экономики Карельского научного иеентра $\rho A H »$, e-mail:m.fyodorova@gmail.com

\title{
РАЗВИТИЕ ТУРИЗМА В ОТАЕАЬНЫХ РЕГИОНАХ СЗФО
}

Аннотауия. Предметом исследования являются наиболее популярные среди отечественных туристов туристские дестинации Северо-Западного Федерального округа (далее СЗФОО) с иелью выявления туристского потенииала этих регионов и возможностей его реализащии. Туристская индустрия в данном случае выступает как альтернативный инструмент развития сельской местности, где повышается экономическая активность местного сообщества за счет командной работы заинтересованных экономических акторов. Методология исследования. Для достижения поставленной чели были применены эмпирические методы исследования, такие как анализ туристских предпочтений по результатам интервью; анализ показателей доходов от туризма в регионе СЗФО и сравнение этих показателей с соседней ФDинляндией, схожей по климатическим условиям и природным туристским ресурсам; сбор и анализ статистической информации по туристским потокам в регионы СЗФО за период с 2005 по 2015; сбор и анализ статистической информации по количеству туристов на душу населения в период 2006-2015. Результаты. В связи с тем, что туризм оказывает важный вклад в экономику региона, дает возможности для создания новых рабочих мест и показал себя наиболее жизнестойким сектором экономики, в статье предложены основные меры по совершенствова-

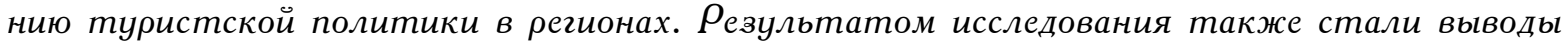
о положении туристских дестинаций СЗФО по отношению друг другу, способы снижения показателей сезонности, предложено перераспределение экономических ролей муниципальных властей, предпринимателей и местного сообщества для наиболее эффективного развития местной экономики сельской местности в регионах СЗФОО. Область применения результатов. Полученные результаты могут быть применены в работе по стратегическому планированию развития регионов СЗФО: в работе местных властей при создании документов планирования, в работе местных сообществ для оценки туристского потенциала территории, возможных «точек роста», необходимых мер по реализачии проектов, направленных на развитие туризма, а также в других регионах с целью развития туристской индустрии.

Ключевые слова: туристская дестинация, стратегическое планирование, развитие туристской дестинации, туристский потенциал, устойчивое развитие, экономическая активность населения.

FEDOROVA MARINA YURIEVNA

Doctoral Student of the FSBIS "Institute of Economics of Karelia Scientific Center of the RAS", e-mail:m.fyodorova@gmail.com

\section{DEVELOPMENT OF TOURISM IN SPECIFIC REGIONS OF THE NCFD}

Abstract. The subject of the study is the most popular tourist destinations of the Northwestern Federal District among the Russians. The goal of the study is to reveal their tourist potential and to analyze the possibilities of its realization. Tourism industry here is considered to be as an instrument to develo $\rho$ rural territories to increase the economic activity of local communities thanks to team work of economic actors. To meet the set objectives the author employed the following empiric methods, the analysis of tourist preferences according questionnaire's results, the analysis of incomes from tourism in the Northwestern Federal District and how it compares to incomes from tourism in Finland, which is similar to the regions of the study by its climatic and nature resources, the collection of the statistics data of the tourist flows to the regions of the Northwest- 
ern Federal District during the period from 2005 to 2015 and its analysis, the collection of the statistics data of the ratio of tourists in the regions of the Northwestern Federal District during the period from 2005 to 2015. As far as tourism contributes a lot to region's economy, generates new job opportunities and showed itself as one of the most viable sector of the economy, the measures to improve tourism policy in regions are proposed in the article. As a result, the author analyzed the situation of the tourist destinations of the Northwestern Federal District to each other, proposed the methods to reduce the seasonality, proposed to redistribute the economic roles of municipal bodies, entrepreneurs and local community to develop local economy of rural territories of the Northwestern Federal District more efficiently. The results can be implemented in the strategic planning of the Northwestern Federal District regions' development. Municipal bodies can use it during the process of working out official planning documents. Local communities can use the study to evaluate tourist potential of their region and possible points of increase, to find out the needed measures to realize projects for tourism development. The study also can be employed in other regions to meet the objectives of tourism development.

Keywords: tourism destination, strategic planning, tourism destination development, tourism potential, sustainable development, economic activity of the population.

Основная цель данной работы - изучить туристический потенциал регионов СЗФО, в частности Республики Карелия, и выработать общие рекомендации для повышения эффективности мероприятий, осуществляемых государством и частным бизнесом в этой отрасли. Актуальность данной проблематики обусловлена значимостью туристической отрасли для развития регионов и тем вкладом, который она вносит в развитие других секторов экономики, включая строительство, сельское хозяйство, услуги и многие другие.

По данным Международного совета по туризму, в 2014 году доля ВВП от туризма и путешествий в мировой экономике составила 7,6\$ триллионов (10\% от мирового ВВП), было создано 277 миллионов новых рабочих мест (т. е. 1 из 11 рабочих мест приходилось на сферу туризма и путешествий) [20]. Согласно утверждению Генерального секретаря ЮНВТО Талеба Рифаи, туризм - «один из наиболее жизнестойких экономических секторов во всем мире, так как создает рабочие места для миллионов людей в эпоху, когда обеспечение перспектив лучшего будущего для жителей всех регионов представляет собой одну из самых сложных проблем. Кроме того, туризм помогает налаживать связи между людьми любого происхождения, из любой страны, разрушает стереотипы и борется со страхом и недоверием» [9]. Важно также помнить о мультипликативном эффекте от туризма в экономику страны и региона, так как он оказывает «воздействие на развитие многих других секторов экономики, включая и гостиничное хозяйство, транспорт, коммуникации, строительство, сельское хозяйство, розничную и оптовую торговлю, общественное питание, банковский и страховой сектор и прочие» [16] .

«По данным Всемирного совета по путешествиям и туризму (WTTC), в 2014 году вклад туризма в ВВП России составил 113,5 млрд долл. США. По этому показателю туризм опережает автомобильную и химическую отрасли промышленности, а также сферу образования. Прямой вклад туризма в ВВП страны - 1,5 \% ВВП (172-е место в мире) - составляет примерно половину доли аграрного сектора страны» [2].

В результате экономических и политических событий 2014 года российские туристы изменили свои предпочтения местам для отдыха, все чаще выбирая отечественные туристские дестинации, а не зарубежные. Девальвация российского рубля также сыграла роль на резком понижении цены на туристский продукт и прочие туристские услуги для иностранных граждан. Развитие социальных сетей с каждым днем дает возможность продвигать любой продукт на любые рынки. В связи с этим автор уверен, что сегодня для отечественного туризма сложилась наиболее благоприятная ситуация, которую важно использовать максимально полезно для эффективного развития индустрии туризма, его позиционирования и продвижения. Устанавливая стратегической целью устойчивое развитие туризма в каждом отдельно взятом регионе, можно добиться повышения уровня и качества жизни местного населения, сделать жизнь в сельской местности более привлекательной для молодежи и тем самым обеспечить приток людей в регионы, повысить культурный уровень местного населения и степень гражданского самосознания. Согласно докладу Всемирного совета по туризму, увеличение трат на внутрен- 
ний туризм - тенденция, которую мы прослеживаем не только в России, но и в мире [20].

В исследовании автор взял за основу регионы Северо-Западного федерального округа (далее - СЗФО), так как, по данным Доклада о состоянии и развитии туризма, в Российской Федерации туризм в них выступает приоритетным направлением развития экономики региона [2]. Сегодня регионы СЗФО очень популярны у туристов, о чем говорят результаты исследования, проведенного национальным рейтингом туристической привлекательности регионов, реализованном центром информационных коммуникаций «Рейтинг» (далее - ЦИК «Рейтинг»). Республика Карелия занимает 7-е место, уступая соответственно Краснодарскому краю, городу федерального значения Санкт-Петербургу, городу федерального значения Москве, Республике Крым, Московской области и Калининградской области [6]. Из других областей СЗФО, присутствующих в исследовании ЦИК «Рейтинг», Ленинградская область занимает 11-е место, Псковская - 16-е место. О туристической популярности регионов СЗФО также свидетельствуют результаты исследования аналитического агентства ТурСтат в 2016 году, где Калининградская область занимает пятое место в номинации «Российский экскурсионный отдых» с 8 \% голосов. В первую пятерку в этой номинации также вошли Хакасия (23\% голосов), Санкт-Петербург (20 \%), Вологодская область (20\%) и Ленинградская область $(14 \%)[5]$.

На основании этих исследований мы можем сделать выводы о приоритетах у российских туристов в области регионального отдыха. В обоих исследованиях российские туристы все чаще отдают предпочтение Калининградскому краю, нежели Республике Карелия. Этому даже не препятствует необходимость покупки авиабилета, так как для сухопутного путешествия требуется как минимум транзитная виза.

Очевидно, что высокий интерес к Калининградской области вызван, во-первых, наличием морской береговой линии на территории региона, а во-вторых, близостью к Европе.

Учитывая особую курортную специфику и более ярко выраженную сезонность таких туристских дестинаций, как Краснодарский край и Республика Крым, можно полагать, что Республика Карелия на сегодняшний день - одна из самых популярных туристских дестинаций с низко выраженной сезонностью и легко доступных для городов-мегаполисов, таких как Москва и Санкт-Петербург. Особое внимание следует уделить тому, что в «Рейтинге» популярности Республика Карелия со значительным отрывом обходит Ленинградскую область, которая находится в непосредственной близости к городу-мегаполису Санкт-Петербургу, откуда его жители могут совершать еженедельные туры выходного дня в область с разными целями.

Рассмотрим основные показатели туристских потоков в регионы Северо-Западного федерального округа (далее - СЗФО), чтобы выявить тенденции туристских потоков.

При работе над статьей автор использовал статистическую информацию в основном из следующих источников: Долгосрочная целевая программа «Развитие сферы туризма и рекреации Ленинградской области на 2010-2015 годы» [3], статья «Развитие сферы туризма в Вологодской области» Величкиной А. В. [11], Публичный доклад о результатах деятельности департамента культуры и туризма в Вологодской области за 2015 год [10], Статистическая информация по туризму департамента культуры и туризма Новгородской области [1], Аналитические справки о развитии туризма в Архангельской области управления развитием туризма министерства культуры Архангельской области [16], статья «Культурно-исторический и природный потенциал как ресурс развития местной экономики» Лагуновой С. В. и Гасаналиевой М. А. [4], статья «Перспективы развития регионального туризма» Прохоровой О. В. [7], Статистическая информация Министерства по туризму Калининградской области [5], Статистические данные по развитию туризма в Республике Карелия Госкомитета Республики Карелия по туризму [13], данные Российского статистического ежегодника 2015 [12].

В соответствии с графиком 1 можно сделать вывод о том, что в 2015 году наибольшее количество туристов посетило Ленинградскую область. В области за последние 10 лет количество туристов неуклонно растет вверх, а в 2014-2015 годах наблюдается резкий скачок вверх. Также важно, что динамика туристских потоков в Ленинградскую область за 10 лет всегда оставалась положительной. На количестве туристов не сказался даже кризис в конце 2009 года, в результате которого, к примеру, снизилось количество туристов в Республике Ка- 
График 1. Динамика числа туристов в СЗФО в период 2005-2015 годов, тыс. чел.

Положительную динамику и более высокие темпы роста количества принятых туристов также демонстрирует Вологодская область. В 2015 году, опередив Республику Карелия, показатели практически приблизились к показателям Ленинградской области. Важно, что за десятилетний период в Вологодской области прирост количества туристов в относительных и абсолютных показателях больше, чем в Ленинградской области.

Несмотря на то, что Республика Карелия - сегодня одно из самых популярных направлений по результатам опросов, за период 2005-2015 годов мы прослеживаем нестабильную динамику количества туристов в республику. Показатели по количеству туристов в 2015 году уступают Ленинградской и Вологодской областям. Причем Ленинградская область начала лидировать уже с 2009 года, а Вологодская - с 2011 года.

Для сравнения взглянем на показатели туристских прибытий в соседнюю Финляндию (согласно данным Туристской ассоциации Финляндии Visit Finland) [15], схожую по климатическим условиям и природным туристским ресурсам. Число только иностранных туристов, посетивших Финляндию в 2015 году, достигает 7,5 миллиона человек. Эта цифра превышает количество туристов в каждом отдельном регионе СЗФО в несколько раз, несмотря на то, что каждый отдельный регион СЗФО, помимо привлекательных и уникальных природных ресурсов, обладает также культурно-историческими ресурсами, которые, несомненно, интересны и отечественным, и заграничным путешественникам. Цена туристской поездки также выступает важным фактором при совершении поездки. Согласно результатам опросов, проведенных среди европейцев в 2013-2015 годах, больше половины интервьюируемых ответили, что не путешествуют по финансовым причинам [19].

Проанализировав статистические показатели динамики числа туристов в СЗФО (график 1), сравнив их с граничащей и схожей по климатическим и природным ресурсам Финляндией, мы можем сделать вывод о том, что на сегодняшний день туристский потенциал регионов СЗФО используется в недостаточной мере, а популярность направления, выраженная в желании посетить туристскую дестинацию, не всегда играет ключевую роль в принятии решения о совершении поездки. Очевидная нестабильность Республики Карелия как туристской дестинации, которая по количеству принятых туристов уже уступает Ленинградской и Вологодской областям, заставляет задуматься о правильности осуществляемой политики в области развития сферы индустрии туризма на территории региона. 
График 2. Количество туристов на душу населения в период 2006-2015 годов.

На графике 2 видно, что наибольшее количество туристов на душу населения в 2015 году приходится на Республику Карелия. Этот показатель в республике неуклонно растет начиная с 2006 года, продемонстрировав спад лишь в 2008 году, когда мы наблюдаем спад у всех регионов СЗФО.

Меньше всего туристов на душу населения в Архангельской области, где показатель не превышает даже оценки в 0,5 человека. Надо сказать, что самым популярным туристским объектом Архангельской области на сегодняшний день выступает Соловецкий ставропигиальный монастырь, находящийся на острове, куда туристы попадают либо самолетами из СанктПетербурга или Архангельска, либо через Карелию на кораблях. Такая организация путешествия делает туристскую продуктовую цепочку очень невыгодной для Архангельской области, потому что, во-первых, в таком случае туристы оставляют минимум денег на территории региона, во-вторых, островное расположение обуславливает резкую сезонность предлагаемого турпродукта. Популярность монастыря уже не нуждается в дополнительной рекламе, а даже наоборот, требует ограничительных мер.

Несмотря на высокие количественные показатели туристских потоков, количество туристов на душу населения в Ленинградской области очень невелико: с 2006 по 2015 год оно увеличилось с 1 до 1,5.

Количество туристов на душу населения в Калининградской области еще меньше: с 2006 по 2015 год изменилось с 0,5 до 1.

Более резкий рост в количестве туристов на душу населения в период с 2006 по 2015 год мы видим в Вологодской области: с 1 до 2.

В Псковской и Новгородской областях показатели по количеству туристов на душу населения также невысоки, что объясняется значительным числом экскурсантов, не совершающих ночевок здесь.

Показатель количества туристов на душу населения важно отслеживать при постановке стратегических целей, связанных с устойчивым развитием туризма в регионе. Согласно Международным методическим рекомендациям расчета статистических показателей туризма, можно увидеть давление, оказываемое или не оказываемое на территорию, а также то, насколько много приезжает туристов в туристскую дестинацию [18]. Кроме того, очевидно, что показатели количества туристов на душу населения говорят о наличии или отсутствии реальной потребности в туристских кадрах и необходимых объектах туристской инфраструктуры. Ситуация с Соловецким архипелагом также свидетельствует о том, что усредненные показатели не всегда отражают реальное положение вещей, когда основная масса туристов приезжает в область посетить только одно наиболее популярное место. Таким образом, общие доходы в экономику региона значительно ниже, чем если бы туристы путешествовали по всей территории 
области или региона, также резко снижается положительный социальный эффект от туризма, но увеличивается антропогенная нагрузка на уникальные природные и архитектурные комплексы, ставя под угрозу их существование.

Что касается доходов от туризма в регионы СЗФО, по данным Долгосрочной целевой программы «Развитие сферы туризма и рекреации Ленинградской области на 2010-2015 годы», в Ленинградской области туризм пока «не является значительным источником дохода в бюджеты всех уровней» [3]. Если сравнивать статистические показатели туризма с Финляндией, где экономика в 2015 году столкнулась с серьезными проблемами, туризм проявил себя с положительной стороны. Согласно данным Туристской ассоциации Финляндии Visit Finland, в 2014 году иностранные туристы потратили в Финляндии 4 биллиона евро, за 2011-2014 вклад туризма в экономику страны составляет 2,5 \% от валового внутреннего продукта; валовая добавленная стоимость, генерируемая туризмом, с 2007 по 2012 годы выросла до 18 \%; особенно с 2007 по 2011 год — тогда индустрия туризма развивалась в 4 раза быстрее [15].

Важный сдерживающий фактор в развитии туризма играет сезонность, когда основные туристские прибытия приходятся на летние месяцы. Это отрицательно сказывается как на доходах в бюджет, так и на возможности развития устойчивого туризма, когда окружающей среде и культурным памятникам посетители не наносят никакого вреда или даже помогают напрямую или опосредованно их восстанавливать и поддерживать. Кроме того, высокая сезонность туризма сказывается на качестве предлагаемого туристского продукта. Загруженность достопримечательностей и популярных туристических мест, а также работников индустрии туризма в «высокий сезон» отрицательно сказывается на имидже места, на представлении о нем, на качестве предоставляемой услуги (Спасо-Преображенский Соловецкий Ставропигиальный монастырь). Такое положение вещей может сформировать негативную оценку потребленной туристской услуги и туристских достопримечательностей и распространить негативную информацию о туристской дестинации в целом. Сезонность - это недостаток развития индустрии туризма в любом регионе и препятствие в достижении стратегической цели развития устойчивого туризма на территории туристской дестинации. Согласно исследованиям Bсемирной туристской организации при $\mathrm{OOH}$, туристы предпочитают путешествовать в пределах собственного региона, «в частности, 4 из 5 туристских прибытий в мире происходит в пределах одного региона» [14]. Более половины туристских поездок совершается с целью отдыха и досуга, $14 \%$ - бизнес-поездки, $27 \%$ - другие цели, такие как поездки к друзьям, родственникам, с религиозными и паломническими целями, с целью укрепления здоровья и лечения [14].

В результате проведенного исследования автор пришел к следующим основным выводам:

1. Несмотря на то, что вклад туризма в экономику регионов остается до сих пор дискуссионным, автор придерживаемся мнения о том, что индустрия туризма оказывает на экономику региона значительное как прямое, так и косвенное положительное воздействие, выраженное не только в финансовых, но и социальном положительном эффектах. Это воздействие может быть недооцененным из-за недооценки косвенного дохода от туризма и неденежных выгод. Развитие туризма позволяет не только добиться повышения уровня и качества жизни местного населения, но и сделать жизнь в регионах более привлекательной для молодежи, остановить отток инициативных и предприимчивых людей в крупные города.

2. Анализ целеполагания в области совершения туристской поездки позволяет утверждать то, что близость туристской дестинации к большим городам-мегаполисам дает возможность снизить показатели сезонности в индустрии туризма. Также важным критерием является наличие рядом аэропорта, развитой транспортной инфраструктуры, высокого качества дорог для осуществления всех видов туристических поездок. Таким образом, мы уверены в том, что преодоление сезонности как важной ступени в достижении цели развития устойчивого туризма в регионе выполнимо в регионах СЗФО, которые располагаются близко к таким городаммегаполисам, как Санкт-Петербург и Москва. Сегодняшняя популярность этих туристских направлений уже была доказана неоднократно социологическими исследованиями и растущими показателями туристских потоков.

3. Очевидно, что развитие дорогостоящей инфраструктуры (транспорт, связь и т. д.) в значительной мере может осуществляться только федеральными и региональными властями. Од- 
нако значительная часть задач должна решаться на муниципальном уровне (выявление и продвижение местных достопримечательностей, обеспечение безопасности, минимального сервиса и т. д.). Также для достижения поставленных целей предпринимателям необходимо работать над повышением качества предоставляемых услуг, ассортиментом предоставляемого туристского продукта и т. д. Развитие современных технологий (специализированные сайты, социальные сети) значительно облегчает предпринимателям (особенно индивидуальным) возможность продвижения своих услуг. В освоении этих технологий (с помощью консультаций, лекций, тренингов и т. д.) им могут оказать содействие общественные организации, инициативные сограждане, а также местные власти, так как это не требует значительных финансовых затрат. Также важно помнить, что для предотвращения возникновения недовольства со стороны местных жителей, для благоприятной гостеприимной среды необходимо, чтобы туристский продукт быть доступен не только жителям мегаполисов, но и местным жителям. Широкая доступность туристского продукта будет способствовать саморекламе и дополнительному вкладу в экономику региона.

\section{Литература}

1. Департамент культуры и туризма Новгородской области. Статистические справки [Электронный peсурс]. - Режим доступа: http://culture.novreg.ru/, свободный. - Загл. с экрана.

2. Доклад о состоянии и развитии туризма в Российской Федераиии в 2014 году // Министерство культуры Российской Федерации. Москва. 2015» [Электронный ресурс]. - Режим доступа: http://mkrf.ru/ upload/mkrf/mkdocs2016/19_04_2016_08.pdf, свободный. —Загл. с экрана.

3. Долгосрочная иелевая программа «Развитие сферы туризма и рекреации Ленинградской области на 2010-2015 годы». Паспорт долгосрочной иелевой программы «Развитие сферы туризма и рекреаиии Ленинградской области на 2010 - 2015 годы»" [Электронный ресурс]. - Режим доступа: http:// center.ivangorod.ru/uslugi/turizm/rekreatsija/164-dcp.html, свободный. - Загл. с экрана.

4. Культурно-исторический и природный потенциал как ресурс развития местной экономики. Лагунова С. В., Гасаналиева М. А // Научно-методический электронный журнал «Конщепт». - 2016. - T. 15. C. 1626-1630. - [Электронный ресурс]. - Режсим доступа: http://e-koncept.ru/2016/96244.htm, свободный. - Загл. с экрана.

5. Министерство по туризму Калининградской области [Электронный ресурс]. - Режим доступа: https://tourism.gov39.ru/, свободный. - Загл. с экрана.

6. Наииональный Туристический Рейтинг (№1) // Центр информаиионных коммуникаиий «Рейтинг» [Электронный ресурс]. - Режсим доступа: http://russia-rating.ru/info/9857.html

7. Перспективы развития регионального туризма. Прохорова О. В. // Молодой ученьий. 2014. № 7.1. - C. 29-33 [Электронный ресурс]. - Режим достуnа: http://moluch.ru/archive/66/11143/, свободный. - Загл. с экрана.

8. Пресс-релиз статьи Департамента культуры Калининградской области [Электронный ресурс]. Режим доступа: http://tourism.gov39.ru/news/2825/, свободный. - Загл. с экрана.

9. Пресс-релиз статьи по числу международных прибытий 2016 году [Электронный ресурс]. - Режим docmyna: http://media.unwto.org/ru/press-release/2016-10-17/v-pervoi-polovine-2016-g-chislo-

mezhdunarodnykh-pribytii-vozroslo-na-4, свободный. - Загл. с экрана.

10. Публичный доклад о результатах деятельности департамента культуры и туризма в Вологодской области за 2015 год. Вологда 2016 [Электронный ресурс]. - Режсим доступа: http://okuvshinnikov.ru/ files/ocenka3/osipovskij.pdf, свободньй. - Загл. с экрана.

11. Развитие сферы туризма в Вологодской области. Величкина А. В. // Современные научные исследования и инновации. 2013. № 6 [Электронный ресурс]. - Pежим docmyna: http://web.snauka.ru/ issues/2013/06/25208, свободный. - Загл. с экрана.

12. Российский статистический ежегодник 2015. // Федеральная служба государственной статистики (Росстат). Москва. 2015. [Электронный ресурс]. - Режим docmyna: http://www.gks.rulfree_doc/ doc_2015/yearlejegod-15.pdf, свободный. - Загл. с экрана.

13. Статистические данные по развитию туризма в Республике Карелия Госкомитета Республики Карелия по туризму [Электронный ресурс]. - Режим достуnа: http://www.gov.karelia.ru/gov/Power/ Committee/Tourism/turstat13.html, свободный. - Загл. с экрана.

14. Стратегия развития туризма в Российской Федераиии на период до 2020 года // Российская газета [Электронный ресурс]. - Режим доступа: https://rg.ru/2014/06/09/turizm-site-dok.html, свободный. Загл. с экрана.

15. Туристская ассоииация Финляндии Visit Finland [Электронный ресурс]. - Режим доступа: http:// www.visitfinland.fi/en/tourism-in-finland/, свободный. - Загл. с экрана.

16. Управления развитием туризма министерства культуры Архангельской области [Электронный peсурс]. - Режим доступа: http://www.pomorland.pro/informatsionno-analiticheskie/, свободный. — Загл. с экрана.

17. Управление развитием туризма в регионе. Опыт реализачии стратегии Республики Карелии / Под общей ред. Ю.В. Савельева, О. В. Толстогузова. - Петрозаводск: Изд-во Карельского научного чентра PAH, 2008. $210 \mathrm{c}$.

18. Ratio of Local Residents to Tourists in Major Tourist Regions and Destinations [Электронный pecypc]. - 
Режим доступа: http://www.un.org/esa/sustdev/natlinfo/indicators/methodology_sheets/demographics/ ratio_localresidents_tourists.pdf, свободный. - Загл. с экрана.

19. Tourism statistics - participation in tourism // European Commission [Электронный ресурс]. - Режим docmyna: http://ec.europa.eu/eurostat/statistics-explained/index.php/Tourism_statistics_-

participation in_tourism, свободный. - Загл. с экрана.

20. Travel \&Tourism Economic Impact 2015 World. // World Travel \& Tourism Council. The Authority on World Travel \& Tourism [Электронный pecypc]. - Режим доступа: http://sete.gr/media/2614/150430economic-impact-2015.pdf, свободный. - Загл. с экрана.

\section{References:}

1. The Department of culture and tourism of the Novgorod region. Statistical reference [Electronic resource]. - Mode of access: http://culture.novreg.ru/ free. The title. screen.

2. A report on the status and development of tourism in the Russian Federation in 2014 // Ministry of culture of the Russian Federation. Moscow. 2015"[Electronic resource]. - Mode of access: http://mkrf.ru/upload/mkrf/ mkdocs2016/19 042016 08.pdffree. The title. screen.

3. Long-term tärget program Development of tourism and recreation in Leningrad region in 2010-2015." The passport the long-term target program Development of tourism and recreation in Leningrad region on 20102015" [Electronic resource]. — Mode of access: http://center.ivangorod.ru/uslugi/turizm/rekreatsija/164dcp.html free. The title. screen.

4. Cultural-historical and natural potential as a resource for the development of the local economy. Lagunova S. V., Gasanaliev M. // Scientific-methodical electronic journal Concept." - 2016. - T. 15. — P. 1626-1630. [Electronic resource]. - Mode of access: http://e-koncept.ru/2016/96244.htm free. The title. screen.

5. The Ministry of tourism of the Kaliningrad region [Electronic resource]. - Mode of access: https:// tourism.gov39.ru/ free. The title. screen.

6. National Tourist Rating (No. 1) // Center for information communications Rating"[Electronic resource]. Mode of access: http://russia-rating.ru/info/9857.html

7. Prospects of development of regional tourism. Prokhorova, O. V. // the Young scientist. - 2014. - No. 7.1. - S. 29-33 [Electronic resource]. - Mode of access: http://moluch.ru/archive/66/11143/ free. The title. screen.

8. Press release article of the Department of culture of the Kaliningrad region [Electronic resource]. - Mode of access: http://tourism.gov39.ru/news/2825/free. The title. screen.

9. Press release articles on international arrivals 2016 [Electronic resource]. - Mode of access: http:// media.unwto.org/ru/press-release/2016-10-17/v-pervoi-polovine-2016-g-chislo-mezhdunarodnykh-pribytiivozroslo-na-4 free. The title. screen.

10. Public report on the results of the activities of the Department of culture and tourism of the Vologda region in 2015. Vologda 2016 [Electronic resource]. - Mode of access: http://okuvshinnikov.ru/files/ocenka3/ osipovskij.pdffree. The title. screen.

11. The development of tourism in the Vologda region. Velichkin, A. V. // Modern scientific researches and innovations. 2013. No. 6 [Electronic resource]. — Mode of access: http://web.snauka.ru/issues/2013/06/25208 free. The title. screen.

12. Russian statistical Yearbook 2015. // Federal state statistics service (Rosstat). Moscow. 2015. [Electronic resource]. - Mode of access: http://www.gks.ru/free_doc/doc_2015/year/ejegod-15.pdffree. The title. screen.

13. Statistical data on tourism development in the Republic of Karelia state Committee of the Republic of Karelia for tourism [Electronic resource]. - Mode of access: http://www.gov.karelia.ru/gov/Power/Committeel Tourism/turstat 13.html free. The title. screen.

14. The strategy of tourism development in the Russian Federation for the period till 2020 // Rossiyskaya Gazeta [Electronic resource]. — Mode of access: https://rg.ru/2014/06/09/turizm-site-dok.html free. The title. screen.

15. Tourism Association of Finland Visit Finland [Electronic resource]. - Mode of access: http:// www. visitfinland.filen/tourism-in-finland/ free. The title. screen.

16. Management of development of tourism of Ministry of culture of the Arkhangelsk region [Electronic resource]. - Mode of access: http://www.pomorland.pro/informatsionno-analiticheskie/ free. The title. screen. 17. Managing the development of tourism in the region. Experience in the implementation strategy of the Republic of Karelia / Under the General editorship of Yu. V. Savel'eva, O. V. Tolstoguzov. — Petrozavodsk: Publishing house of the Karelian research centre RAS, 2008. $210 \mathrm{~S}$.

18. Ratio of Local Residents to Tourists in Major Tourist Regions and Destinations [Electronic resource]. Mode of access: http://www.un.org/esa/sustdev/natlinfo/indicators/methodology_sheets/demographics/ ratio_localresidents_tourists.pdffree. The title. screen.

19. Tourism statistics - participation in tourism // European Commission [Electronic resource]. — Mode of access: http://ec.europa.eu/eurostat/statistics-explained/index.php/Tourism_statistics_participation in tourism free. The title. screen.

20. Travel \& Tourism Economic Impact 2015 World. // World Travel \& Tourism Council. The Authority on World Travel \& Tourism [Electronic resource]. - Mode of access: http://sete.gr/media/2614/150430economic-impact-2015.pdffree. The title. screen. 